Digitalizacja archiwalnych numerów czasopisma naukowego Analecta Cracoviensia 1-24 (1969-1992) i ich publikacja w otwartym dostępie - zadanie finansowane w ramach umowy 672/P-DUN/2017 ze środków Ministra Nauki i Szkolnictwa Wyższego przeznaczonych na działalność upowszechniającą naukę

\title{
WSPÓŁCZESNA INTERPRETACJA LOGIÓW O SYNU CZKOWIECZYM
}

1. Wybitny egzegeta szkoły lowańskiej, Józef Coppens stwierdził w r. 1980, że ,ze wszystkich tytułów chrystologicznych, rozpowszechnionych w Kościele apostolskim, tytuł Syna Człowieczego jest najbardziej wieloznaczny i bez wątpienia najbardziej kontrowersyjny, zaś poglądy dotyczące jego właściwego znaczenia, a zwłaszcza jego początków, ewentualnie także jego użycia przez samego Jezusa - najbardziej rozbieżne" ${ }^{1}$. Z podobnym stwierdzeniem spotykamy się u dogmatyka Waltera Kaspera: „Słowa te (sc. o Synu Człowieczym) są jednym z najtrudniejszych problemów Nowego Testamentu, a badiania naukowe dalekie są jeszcze od - nawet w przybliżeniu - jednoznacznej i zgodnej interpretacji ich pochodzenia i sensu" ". Mimo trudności interpretacyjnych studium tytułu „Syn Człowieczy” jest niezmiernej wagi dla egzegezy i teologii. Podkreśla to znany egzegeta protestancki F. Hahn: „Ze wszystkich tytułów chrystologicznych 'Syn Człowieczy' jest studiowany najbardziej dokładnie. Wynika to $\mathrm{z}$ faktu, że poprzez ten tytuł chwały zamierza się dotrzeć do samego centrum przepowiadania Jezusa. (...) Studium tytułu 'Syn Człowieczy' jest zatem najbardziej właściwym punktem wyjścia dla badania najstarszych tradycji chrystologicznych" ${ }^{3}$.

Wypada zatem zająć się niektórymi aspektami tej problematyki tytułu Syna Człowieczego, zakładając od początku, że ani nie chodzi tutaj - wyczerpanie zagadnienia, ani też o wyprowadzenie jednoznacznych i zadowalających wniosków. Syntetyczne naszkicowanie problematyki jest celem niniejszego przedstawienia. Stąd usprawiedliwienie tytułu wypowiedzi: współczesna interpretacja, a nie: interpretacje - jakby to mogło wynikać z różnorodności proponowanych rozwiązań.

Trzeba zauważyć, że bibliografia dotycząca zagadnienia Syna Człowieczego jest przeobfita. J. Coppens, który pod koniec swego życia pilnie zajmował się tym zagadnieniem i którego przeto można by nazwać „egze-

1 Où en est le problème de Jésus „Fils de l'homme”, „Ephem. Theol. Lovan.” $56(1980)$ s. $282-302$. Cytat ze s. 282.

2 Jezus Chrystus. Przeł. B. Białecki, Warszawa 1983, s. 105. (Tytuł oryg.: Jesus der Christus).

s Christologische Hoheitstitel (FRLANT 83), Göttingen 41974, s. 15 (11963). 
getą Syna Człowieczego" w pismach tak Starego, jak i Nowego Testamentu, sporządził bibliografię za okres 1900-1980, liczącą ponad 300 pozycji ${ }^{4}$. Na pewno nie są to wszystkie pozycje, lecz te, które zauważa egzegeza zachodnia ${ }^{5}$.

2. Przypomnijmy status quaestionis. Pojęcie "Syn Człowieczy” występuje w Nowym Testamencie osiemdziesiąt razy i z wyjątkiem jednego miejsca w Dz 7, 56, jest używane tylko przez samego Jezusa ${ }^{6}$. Najczęściej występuje u Synoptyków, ale jest również obecne w Ewangelii Janowej; poza ewangeliami zachodzi tylko we wzmiankowanym wyżej miejscu Dz 7, 56 i dwukrotnie - jako cytaty z Dn 7 - w Apokalipsie $(1,13$ i 14,14$)$. Rzecz ciekawa — „Syn Człowieczy" nie występuje nigdy $\mathrm{w}$ listach Pawłowych ani $\mathrm{w}$ innych listach, a więc $\mathrm{w}$ pismach wyraźnie teologicznych Nowego Testamentu ?

Tytuł Syna Człowieczego odnosił Jezus do trzech kontekstów Swojego życia i działalności ${ }^{8}$ :

— różne sytuacje życia ziemskiego (ok. 20 razy);

- męka i zmartwychwstanie (25 razy);

- paruzja (30 razy).

Mamy również w tekstach ewangelicznych połączenie Syna Człowieczego z preegzystencją $(\mathrm{J} 3,13)$. „Jezus bez wątpienia wolał nazywać

4 Art. cyt., s. 283 nn.

5 Panoramę studiów nad problemem Syna Czlowienczego oprócz J, Coppensa podają (wyliczam tylko ostatnie pozycje): I. H. Marschall, The Synoptic Son of Man Sayings in Recent Discussion, "New Test. Studies" 12(1965-66), s. 327351 ; tenże, The Son of Man in Contemporary Debate, "Evangelical Quarterly" $42(1970)$, s. $67 \longmapsto 87$; G. H a u f e, Das Menschensohnproblem in der gegenwärtigen wissenschaftlichen Diskussion, „Evangelische Theologie” 26(1966), s. 130-14i1; $\mathrm{S}$. Légasse, Jésus historique et le Fils de l'homme. Aperçu sur les opinions contemporaines, w: Apocalypses et théologie de l'espérance (Lectio divina 95), Paris 1977, s. 271-298; W. G. K ü m m e 1, Jesusforschung seit 1965, V. Der persönliche Anspruch Jesu. Die Menschensohnfrage, ,Theol. Rundschau” 45(1980), s. 50814; Nachträge 1975-1980, tamże 47(1982), s. 369-378; G. G er lem a n, Der Menschensohn (Studia Biblica 1), Leiden 1983.

" W wypadku J 12, 34 thum podiejmuje nazwę „Syn Człowieczy” jako reakicja na słowa Jezusa. Jest to reakcja zdziwienia na ten tytuł w ustach Jezusa. Nie miał racji J. Wellhausien, gdy z końcem XIX w. pisał, że tytuł Syna Człowieczego, uży'wany przez Jezusa, nie budził zdiziwienia słuchaczy (Skizzen und Vorarbeiten VI, Berlin 1899, s. 197). Argumentację Wellhausena podjął ostatnio G. Vermès, ale nieprzekonująco (Jesus the Jew, London. Tlum. włoskie: Gesù l'ebreo, Roma '1983, S. $183 \mathrm{n})$.

7 L. S a b ourlin (Les noms et les titres de Jésus, Bruges-Paris 1963, s. 201204) utrzymuje, że tytuł Syna Człowieczego - jakkolwiek nieobecny w Corpus Paulinum - inspiruje wiele ważnych tekstów teologii Pawłowej, jak np., ,pierwszy czlowiek" (1 Kor 15, 45-49), ,człowiek" (1 Kor 15, 21. 47) czy kenoza (Flp 2, 5-8). Już J. D u p o n t (,Revue Biblique”, 1962, s. 58, nota 32) zwracal uwagę, że odnośnie do tekstu 1 Ties 1, 10: ,oczekiwać z nieblios Jego (Boga) Syna, którego wzbudził z martwych, Jezusa", można zastanawiać się nad Pawłową transpozycją tematu Syna Czlowieczego.

8 Por. K. H. S chelkle, Theologie des Neuen Testaments, II. Gott war in Christus, Düisseldorf 1973, s. 199-207. 
się Synem Człowieczym - utrzymuje L. Sabourin ${ }^{9}$ - ponieważ ten tytuł mógł odpowiadać trzem aspektom Jego życia i dzieła: preegzystencja, życie ziemskie, życie przyszłe. Co więcej, nieokreślony charakter pojęcia Syna Człowieczego i jego niesprecyzowane asocjacje służyły stopniowemu objawieniu tajemnicy mesjańskiej. Jezus dał wyrażeniu 'Syn Człowieczy' nowe znaczenie - On go nie wynalazł'.

Takie jest klasyczne stanowisko egzegezy katolickiej.

3. Analizując poglądy współczesnych egzegetów moglibyśmy wyodrębnić pięc grup autorów ${ }^{10}$.

3.1. Do pierwszej grupy zaliczymy autorów, którzy twierdzą radykalnie, że logia o Synu Człowieczym nie dochodzą do Jezusa (Ph. Vielhauer, H. Conzelmann, E. Käsemann).

3.2. Druga grupa autorów, nie mniej radykalna, podtrzymuje autentyczność tych logiów (P. Benoit, A. Feuillet, O. Cullmann).

3.3. Wśród autorów podtrzymujących autentyczność logiów należy wyróżnić nielicznych, którzy odnoszą logia do ziemskiej działalności Jezusa (E. Schweizer, J. P. Brown).

3.4. Większa grupa autorów przypisuje logia Synowi Człowieczemu w życiu przyszłym, eschatologicznym, paruzyjnym. Różnią się oni jednak między sobą co do zakresu ilości logiów uważanych za autentyczne i ich interpretacji. J. Coppens na przykład przyjmuje tylko cztery logia Markowe za autentyczne (Mk 8, 38; 9, 12;13, 26;14,62).

3.5. Nie brak w końcu i takich autorów współczesnych, którzy nie wypowiadając się wyraźnie za identyfikacją logiów z tą czy inną postacią Mesjasza przyjmują, że tytuł ten był przez Jezusa i chciany, i używany (J. Jeremias, E. Tödt, C. Colpe).

W egzegezie logiów o Synu Człowieczym pojawiają się dwie zasadnicze trudności. Pierwsza dotyczy lingwistycznej warstwy tego wyrażenia, druga natomiast odnosi się do interpretacji Dn 7, 14. Omówimy pokrótce obydwie trudności, gdyż od ich rozwiązania zależy właściwa interpretacja logiów.

4. Trudność natury lingwistycznej dotyczy dwóch momentów:

- substratu aramejskiego tytułu ,Syn Człowieczy ;

- rozpowszechnienia się tego wyrażenia w literaturze aramejskiej.

Rozpatrzmy po kolei poszczególne zagadnienia.

4.1. Nie ulega wątpliwości, że greckie wyrażenie „Syn Człowieczy”: hyios tou anthrōpou posiada aramejski substrat bar nāš lub bar nāšă', (forma determinata).

G. Vermès utrzymuje, że wyrażenie $b r n \check{s} / / b r$ nš nie figuruje w języ-

Dz. cyt., s. 193 n.

${ }^{10}$ Zoib. J. C o p pen s, Où en est le problème, s. $282 \mathrm{n}$. 
ku aramejskim jako tytuł mesjański, lecz jest synonimem człowieka w charakterze zaimka nieokreślonego i pełni funkcję wyrażenia obiegowego zastępującego pierwszą osobę w narracji ${ }^{11}$. Wydaje się, że wywody egzegety oksfordzkiego nie są zbyt dobrze udokumentowane: zwrócili na to uwagę tacy znawcy aramejskiego, jak M. Black ${ }^{12}$, J. Jeremias, R. Le Déaut czy J. A. Fitzmyer ${ }^{13}$. Nie można utożsamiać dwóch podobnych wyrażeń aramejskich: hahu gabra = "ten człowiek" i bar nāš $\bar{a}$ ' = „syn człowieczy”. Jeśli to pierwsze wyrażenie oznacza wyłącznie „ja”, to drugie jest zwrotem ogólnym mogącym również oznaczać tego, który mówi. Poza tym Vermès opiera swoje wywody na materiale filologicznym dość obcym dla Nowego Testamentu. Możemy zgodzić się ze stanowiskiem, jakie w tej sprawie zająl rozsądnie C. H. Dodd ${ }^{14}$ : „Nie ma dostatecznych dowodów, żeby w żydowskich środowiskach epoki Jezusa używano wyrażenia 'Syn Człowieczy' jako tytułu równoznacznego z tytułem 'Mesjasz' czy w ogóle jako konkretnego tytułu. (...) Jeśli Jezus posługiwał się owym pospolitym wyrażeniem nie w sposób przypadkowy, lecz w okolicznościach, które z tej frazy czyniły częściowo zawoalowane stwierdzenie powołania, to 'Syn Człowieczy' stał się dla Jezusa jak gdyby określeniem samego siebie, zastępującym tradycyjny tytuł 'Mesjasz'. Zdaje się, że tak właśnie pojmowali ową frazę autorzy Ewangelii".

4.2. Innym zagadnieniem jest rozpowszechnienie się $w$ środowisku judaistycznym tytułu „Syn Człowieczy” jako tytułu mesjańskiego. Łączy się to $\mathrm{z}$ datacją ważnego $\mathrm{w}$ tym względzie dokumentu, jakim jest $\mathrm{He}$ noch etiopski, a zwłaszcza część zwana Księga Przypowieści. J. T. Milik uważa ostatnio Księgę Przypowieści za twór chrześcijański pochodzący z ok. 270 r. po Chr. Opinia ta jednak nie zyskała wielu zwolenników. Egzegeci raczej opowiadają się za pochodzeniem żydowskim tego pisma; chrześcijaństwo co najwyżej mogło być niejako katalizatorem (posługując się porównaniem P. Grelota) przyśpieszającym redakcję Księgi Przypowieści. Natomiast co do czasu powstania rozbieżność poglądów jest duża: od ery przedchrześcijańskiej do lat 150 ery chrześcijańskiej.

11 Gesù l'ebreo, s. 207, 220. Tenże, The Present State of the "Son of Man" Debate, "Journal of Jewish Studies" 29(1978), s. 123-134.

12 Charakterystyczne jest stanowisko M. Blacka, który zachęcił G. Vermésa do publikacji jego tezy jako appendyksu w książce An Aramaic Approach to the Gospels and Acts, Oxford ${ }^{3} 10 i 67$, s. $3110-330$, ale zaraz też ogłosił swoje zastrzeżenia: w logiach o Synu Czlowieczym nie można zaprzeczyć konotacji eschatologicznej (tamże, s. 328-330). Apendyks Vermésa ukazal się później w pracy tegoż Post-biblical Jewish Studies (Studies in Judaism in Late Antiquity 8), Leiden 1975, s. $147-165$.

${ }_{13}$ Zob. G. Vermés, Gesù l'ebreo, s. 219—223.

14 The Founder of Christianity, New York 51974 . Cytat z polskiego przekładu Z. Kubiaka (Założyciel chrześcijaństwa, Editions du Dialogue, Paris 1978, s. 121n., 123). 
Wielu egzegetów obecnie twierdzi, że nie chodzi w Księdze Przypowieści Henocha o prawdziwy tytuł ${ }^{15}$. Jezus używając wyrażenia „Syn Człowieczy" nie musiał zwracać się do Księgi Henocha, wystarczyło oparcie $w$ proroctwie Daniela ${ }^{16}$. Księga Henocha pozostaje jednak jako ś wi a d e c t wo użycia wyrażenia "Syn Człowieczy” w środowisku Jezusa - wyrażenia, któremu dopiero sam Jezus nadaje specyficzny charakter ${ }^{17}$.

5. Możemy się zgodzić, że Jezus nie musiał sięgać do koncepcji Księgi Przypowieści w wyborze tytułu Syna Człowieczego, wystarczył tekst i kontekst Dn 7, 13 o Synu Człowieczym. Jezus jako nauczyciel połączył metodą ówczesnej egzegezy midraszowej różne topoi - miejsca w Księdze Daniela. Tak więc w Dn 7, 13 mamy tajemniczą postać Syna Człowieczego, będącą reprezentantem „świętych Najwyższego", którzy będą wytraceni (Dn 7, 21. 25b). Jest więc misja Mesjasza połączona z cierpieniem - jest to Syn Człowieczy cierpiący. Ale mamy dalej w Dn 12, 2-3 zapowiedź eschatologicznego zmartwychwstania: „święci Najwyższego" to "mądrzy", mistrzowie sprawiedliwości „będą świecić jak blask sklepienia", ,jak gwiazdy przez wieki i na zawsze”. Połączenie zatem cierpienia Syna Człowieczego z jego chwalebnym zmartwychwstaniem nie jest wcale trudne. Połączenie takie dokonało się $\mathrm{w}$ ustach Jezusa, mistrza interpretacji tekstów Starego Testamentu.

6. Mimo rozbieżności poglądów na interpretację logiów o Synu Człowieczym możemy zgodzić się co do następujących rzeczy ${ }^{18}$ :

6.1. Tytuł „Syn Człowieczy” sięga nie tylko czasów Jezusa, lecz jest przyjęty wprost przez samego Jezusa jako wyraz medytacji teologicznej nad tekstami Pisma. Nie mógł być wytworem pierwotnego Kościoła, gdyż został szybko w tradycji biblijnej porzucony. Ponieważ jednak przetrwał w niektórych pismach judeochrześcijańskich, jak Ewangelia Hebrajczyków, Ewangelia Tomasza czy pisma klementyńskie, można przypuszczać, że był rozpowszechniony w kręgu judeochrześcijaństwa hellenistycznego.

6.2. $\mathrm{Z}$ punktu widzenia językowego substratem tego tytułu jest

15 Por. G. Viermés, Gesù l'ebreo, s. 1202-207; J. Coppeins, Où en est le problème, s. $289 \mathrm{n}$.

16 Por. M. D. H o ok er, Is the Son of Man Problem Really Insoluble?, w: Text and Interpretation. Festschrift M. Black, Cambridge 1978, s. 155-166.

17 „Le témoignage du Livre des Paraboles et celuli des Evangiles suffilsent à établir que le Judaisme contemporain de Jésus et du Christianisme naissant n'ont pas perdu de vue le Fils de l'homme daniélique" - stwierdza J. Coppens, Le Fils d'homme dans les traditions juives postbibliques hormis le Livre des $\mathrm{Pa}$ raboles de l'Hénoch éthiopien, „Ephem. Theol. Lovan.” 57(1981), s. 58-82. Cytat ze s. 81.

18 Por. Ch. Perrot, Jésus et l'histoire, Tournai 1979.

14 - Analecta Cracoviensia 
ben 'adam lub bar 'enaš, a dla greckiej formy hyios tou anthropou; aram. forma emfatyczna bar nāšă'. Jest to wyrażenie wieloznaczne i wielowarstwowe. Zawiera w sobie dwa semy: „Syn” - filiacja i „Człowieczy" - pochodzenie ludzkie. Może również oznaczać pierwszą osobę liczby pojedynczej ,ja” lub po prostu konkretnego człowieka w znaczeniu „ten oto człowiek" (aram. hahu gabra).

6.3. Wspólnota pierwotna zachowała ten tytuł, ponieważ jest to własny sposób mówienia Jezusa o sobie samym. Łączy on „Ja” osoby Jezusa $\mathrm{z}$ postacią Mesjasza cierpiącego i chwalebnego, $\mathrm{z}$ jego misją założenia Królestwa Bożego (basileia). To jest równocześnie kryterium autentyczności logiów, w których wyrażenie „Syn Człowieczy” jest obecne.

\section{LES LOGIA DU FILS DE L'HOMIME DANS LA DISCUSSION D'A.UJOURD'HUI}

\section{R és u m é}

De tous les titres christologiques celui de „Fils de l'homme” est le plus ambigu et le plus controversé. De même, l'éventail des' opinions est large et varié. La bibliographie du sujet est abondante. J. Coppens a dressé un aperçu des diverses contributions, de 1000 à 1980 , comprenant plus que 300 numéros. Nous avons à nous reporter aux études qui nous livrent d'excellents aperçus du problème et des solutionls y apportées. En nous insipirant de ces aperçus, nous essayons de dresser un étalt de la question et de préciser vers quelle solution - dans la mesure où celle-ci s'avère possible - les recherches s'orientent.

On peut classer, après J. Coppens, les opinions des exégètes en cinq groupes. Une majorité d'auteurs opte pour les logia sur le Fils de l'homme futur, eschatologique.

Deux questions préalables conditionnent l'enquête sur le Fils de l'homme. La première est d'ordre linguistique: il s'agit des origines et de la signification de l'expression araméenne bar nāš, ,fils d'homme". La seconde concerne l'analyse de l'expression en fonction de son usage à l'époque de Jésus et du christianisme naissant.

En dépit de divergence des oplinions concernant l'interprétation des logia du Fils de l'homme, on peut s'accorder quant à quelques conclusions:

1. Jésus, lui-même, s'est servi de l'expresion „Fils de l'homme” comme un titre, car il est invraisemblable que la communauté chrétienne primitive ait forgé cette expresstion, vu qu'elle est absente des écrits pauliniens et a été presque aussitôt abandonnée.

2. Au point de vue linguistique, le substrat du titre est ben 'adam/bar 'enāš ou la forme emphatique bar $n \bar{a} \breve{s} \bar{a}$. Cette expresion est fort ambiguë. Elle concerne la fillialtion et l'humanité, elle peuit remplacer le pronom de la première perisonne.

3. La communauté primitive conserva pour Jésus le titre "Fils de l'homme", parce qu'il se réfère directement au Fils d'homme daniélique (Dn 7, 13) et établit un lien entre le Messie souffrant et glorieux. 